\title{
NITRIC OXIDE ACTIVITY IN PATIENTS UNDERGOING CARDIOPULMONARY BYPASS
}

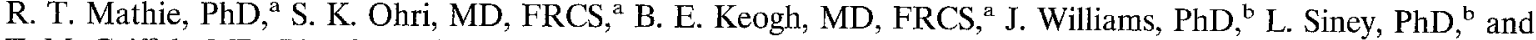 \\ T. M. Griffith, MD, $\mathrm{PhD},{ }^{\mathrm{c}}$ London and Cardiff, United Kingdom
}

It is well known that cardiopulmonary bypass (CPB) causes major hemodynamic and physiologic disturbances. These may be alleviated by replacing conventional nonpulsatile perfusion with pulsatile flow, which under normothermic conditions results in a lower peripheral vascular resistance, associated with lower plasma angiotensin II and vasopressin levels. ${ }^{1,2}$ It is also known that release of the endogenous vasodilator nitric oxide (NO) is sensitive to flow pulsatility, ${ }^{3,4}$ a mechanism that may contribute to the improved peripheral hemodynamics associated with pulsatile perfusion. We therefore tested the hypothesis that higher NO activity is associated with pulsatile flow than with nonpulsatile flow during and immediately after normothermic CPB. We also investigated whether hypothermic CPB modulated any observed differences.

Twenty-four patients without diabetes who were undergoing elective $\mathrm{CPB}\left(2.4 \mathrm{~L} \cdot \mathrm{min}^{-1} \cdot \mathrm{m}^{-2}\right)$ for coronary artery bypass grafting were randomly assigned to four groups: $37^{\circ} \mathrm{C}$ with pulsatile flow, $37^{\circ} \mathrm{C}$ with nonpulsatile flow, $28^{\circ} \mathrm{C}$ with pulsatile flow, and $28^{\circ} \mathrm{C}$ with nonpulsatile flow ( $n=6$ per group). There were no differences among the groups with respect to age (mean for 24 patients of 59.3 years), number of arteries grafted (median for all groups of 3), crossclamp time (mean for 24 patients of 33.9 minutes), or smoking habits. The same anesthetic regimen (methohexitone, fentanyl, midazolam, and enflurane) was employed for all subjects. Preoperative use of $\beta$-blockers, calcium antagonists, oral nitrates, and aspirin did not differ among the groups; any nitrate medications were discontinued at least 12 hours before operation and were not recommenced until after our investigation. In each patient, arterial blood pressure, cardiac output (by thermal dilution), and gastric mucosal blood flow (by laser Doppler velocimetry) were measured, and peripheral vascular resistance was calculated. Sampling of peripheral venous blood for plasma nitrite plus nitrate (index of NO activity) was achieved at the following time points: 45 minutes after induction of anesthesia (time point $\mathrm{A}$, baseline); 10 minutes (B) and 20 minutes (C) after commencement of CPB; 10 minutes after release of the aortic crossclamp (D); and 10 minutes (E) and 30 minutes (F) after CPB was discontinued. Plasma nitrite plus

From the Department of Surgery, Royal Postgraduate Medical School, London, ${ }^{\mathrm{a}}$ and the Departments of Pharmacology ${ }^{\mathrm{b}}$ and Diagnostic Radiology, ${ }^{c}$ Cardiovascular Sciences Research Group, University of Wales College of Medicine, Cardiff, United Kingdom.

Received for publication Feb. 13, 1996; accepted for publication Feb. 20, 1996.

J Thorac Cardiovase Surg 1996;112:1394-5

Copyright (C) 1996 by Mosby-Year Book, Inc.

$0022-5223 / 96 \$ 5.00+0 \quad \mathbf{1 2 / 5 4 / 7 2 9 0 2}$ nitrate was measured in thawed samples by chemiluminescence or by a gas chromatographic method employing electron-capture detection, against standards common to each.

Arterial blood pressure, peripheral vascular resistance, and gastric mucosal blood flow fell in all groups during CPB. Gastric mucosal flow was reduced to a greater extent in the $28^{\circ} \mathrm{C}$ with nonpulsatile flow group than in the $28^{\circ} \mathrm{C}$ with pulsatile flow group (to $39 \% \pm 15 \%$ and to $63 \% \pm 22 \%$ of baseline, respectively; $p<0.05$ ). Cardiac output, maintained at normal baseline levels during CPB, increased by $25 \%$ to $30 \%$ in all groups immediately after CPB. During CPB (time point $\mathrm{C}$ ), plasma nitrite plus nitrate was $134 \% \pm 15 \%$ of baseline in the $37^{\circ} \mathrm{C}$ with pulsatile flow group, compared with $80 \% \pm 16 \%$ in the $37^{\circ} \mathrm{C}$ with nonpulsatile flow group $(p<0.05)$. Moreover, values of nitrite plus nitrate in the $37^{\circ} \mathrm{C}$ with nonpulsatile flow group were significantly lower $(p<0.05)$ immediately after $\mathrm{CPB}$ (timepoint $\mathrm{E}$ ) than at the equivalent time in the $37^{\circ} \mathrm{C}$ with pulsatile flow group (Table I). By contrast, nitrite plus nitrate levels in the $28^{\circ} \mathrm{C}$ with nonpulsatile flow group were significantly higher $(p<0.05)$ than in the $28^{\circ} \mathrm{C}$ with pulsatile flow group 10 minutes after crossclamp removal (timepoint $\mathrm{D}$, Table I).

These findings support the view that ambient release of NO may be greater during pulsatile, normothermic perfusion than during nonpulsatile flow. Diminished NO release after nonpulsatile, normothermic perfusion compared with pulsatile perfusion at the same temperature was also evident. The indexes of peripheral vascular blood flow and resistance did not suggest a more vasodilated peripheral vasculature in these patient groups at the time points at which relative increases in plasma nitrite plus nitrate were observed. The peripheral vascular resistance during CPB was just above $50 \%$ of baseline in all our patients, however, which may indicate that the anesthetic technique we employed resulted in a highly dilated peripheral vasculature, ${ }^{5}$ masking any specific hemodynamic benefits of altered NO release. This effect of pulsatility on NO release did not appear to take place during or after hypothermic CPB; indeed, NO release was augmented during hypothermic nonpulsatile perfusion after removal of the aortic crossclamp. This increased release of NO with nonpulsatile CPB may indicate an adaptive response of the peripheral vasculature to the restoration of a normal circulation associated with rewarming. The pronounced vasoconstriction that we detected in the splanchnic bed under nonpulsatile, hypothermic conditions suggests regional differences in the hemodynamic effects of CPB and possibly NO synthesis at low temperatures, which may account for our findings. It is already recognised that splanchnic blood flow in particular may be optimized during CPB by pulsatile perfu- 
Volume 112, Number 5

Table I. Plasma nitrite plus nitrate concentrations ( $\mu \mathrm{mol} / L$ ) in patients undergoing CPB

\begin{tabular}{ccccc}
\hline Time point & $37^{\circ} \mathrm{C}$ with pulsatile flow & $37^{\circ} \mathrm{C}$ with nonpulsatile flow & $28^{\circ} \mathrm{C}$ with pulsatile flow & $28^{\circ} \mathrm{C}$ with nonpulsatile flow \\
\hline A & $30.3 \pm 12.4$ & $41.3 \pm 4.8$ & $37.8 \pm 13.8$ & $47.2 \pm 8.9$ \\
B & $33.8 \pm 14.8$ & $39.6 \pm 12.6$ & $27.4 \pm 6.1$ & $52.6 \pm 7.6$ \\
C & $38.6 \pm 15.5$ & $35.3 \pm 7.4$ & $32.7 \pm 13.1$ & $45.7 \pm 13.3$ \\
D & $30.9 \pm 12.1$ & $36.6 \pm 8.5$ & $22.7 \pm 8.7$ & $66.5 \pm 11.3^{*}$ \\
E & $34.0 \pm 10.2$ & $23.1 \pm 3.3^{* \dagger}$ & $26.7 \pm 10.0$ & $51.0 \pm 10.9$ \\
F & $35.1 \pm 13.7$ & $30.6 \pm 9.1$ & $34.2 \pm 14.9$ & $51.8 \pm 12.4$
\end{tabular}

Timepoints defined in text. Values presented as mean \pm standard error of the mean.

${ }^{*}$ Significant difference from isothermic pulsatile flow group at same time point $(p<0.05)$.

$\uparrow$ Significant difference from time point $\mathrm{A}$ in same group $(p<0.05)$.

sion at $37^{\circ} \mathrm{C}^{5}$ The cause of the elevated plasma nitrite plus nitrate levels in this group is unlikely to have been simply the release of stored metabolites built up during aortic crossclamping because the same effect was not observed in the other three groups, in which an identical manouver was performed. Our results clearly indicate the need for further studies designed to examine in greater detail the regional hemodynamic effects of NO associated with pulsatile perfusion and hypothermia.

\section{REFERENCES}

1. Taylor KM, Casals JG, Mittra SM, Brannan JJ, Morton IJ. Haemodynamic effects of angiotensin converting enzyme inhibition after cardiopulmonary bypass in dogs. Cardiovasc Res 1980;14:199-205.
2. Levine FH, Philbin DM, Kono K, Coggins CH, Emerson CW, Austen WG, et al. Plasma vasopressin levels and urinary sodium excretion during cardiopulmonary bypass with and without pulsatile flow. Ann Thorac Surg 1981;32:63-7.

3. Pohl U, Busse R, Kuon E, Bassenge E. Pulsatile perfusion stimulates the release of endothelial autacoids. J Appl Cardiol 1986;1:215-35.

4. Hutcheson IR, Griffith TM. Release of endothelium-derived relaxing factor is modulated both by frequency and amplitude of pulsatile flow. Am J Physiol 1991;261(1 Pt 2):H257-62.

5. Taylor KM. Pulsatile and non-pulsatile perfusion. In: Minami K, Körfer R, Wada J, editors. Cardio-thoracic surgery: what's new in current practice. Amsterdam: Excerpta Medica, 1992: $57-65$.

\section{VIDEO-ASSISTED THORACOSCOPIC LOCAL EXCISION OF PULMONARY ARTERIOVENOUS FISTULA}

Masato Minami, MD, Yoshitaka Fujii, MD, Takatoshi Mizuta, MD, Hiroki Kishima, MD, and Hikaru Matsuda, MD, Osaka, Japan

Recent advances in therapeutic embolization have made nonsurgical treatment of pulmonary arteriovenous malformation preferred over conventional surgical excision., ${ }^{1,2}$ In embolization therapy there is a possibility of incomplete treatment and a risk of accidental systemic embolization, ${ }^{3}$ however, so surgical excision is considered appropriate for at least some patients. In such cases, conservative operation, such as wedge resection and local excision, is desirable if possible. In this report, video-assisted thoracoscopic surgical

From the First Department of Surgery, Osaka University Medical School, Suita, Osaka, Japan.

Received for publication April 8, 1996; accepted for publication April 17, 1996.

J Thorac Cardiovase Surg 1996;112:1395-7

Copyright (C) 1996 by Mosby-Year Book, Inc.

$0022-5223 / 96 \$ 5.00+0 \quad \mathbf{1 2 / 5 4 / 7 4 1 7 8}$ technique, which has recently been applied to a variety of thoracic lesions, was adopted as a less invasive modality to excise a pulmonary arteriovenous fistula (PAVF).

A 35-year-old man was referred for a nodule in the right middle field that was found on a chest roentgenogram. He had no symptoms but had a continuous murmur on the right side of the anterior chest. A computed tomogram showed a $2 \mathrm{~cm}$ PAVF just beneath the visceral pleura in subsegment $3 \mathrm{~b}$ of the right upper lobe, which was fed from the dilated A. lobi sup. vent. medialis and drained to V. ventralis superior. There were no other lesions. Pulmonary arteriography revealed a noncavernous, well-demarcated PAVF with single feeder and drainage vessels (Fig. 1). Blood hemoglobin content was $16.4 \mathrm{gm} / \mathrm{dl}$. Arterial blood gas analysis showed an arterial oxygen tension of 84 $\mathrm{mm} \mathrm{Hg}$, an arterial carbon dioxide tension of $38 \mathrm{~mm} \mathrm{Hg}$, and an arterial oxygen saturation of $95 \%$. Shunt fraction was estimated at $19 \%$. 